\title{
Assessment of oxide nanoparticle stability in liquid phase transmission electron microscopy
}

\author{
Mark J. Meijerink, Krijn P. de Jong, and Jovana Zečević ( $\square$ ) \\ Inorganic Chemistry and Catalysis, Debye Institute of Nanomaterials Science, Utrecht University, Universiteitsweg 99, 3584 CG Utrecht, The Netherlands
}

(C) The Author(s) 2019, corrected publication 2019.

Received: 28 February 2019 / Revised: 12 April 2019 / Accepted: 15 April 2019

\begin{abstract}
Studying liquid phase nanoscale dynamic processes of oxide nanoparticles is of considerable interest to a wide variety of fields. Recently developed liquid phase transmission electron microscopy (LP-TEM) is a promising technique, but destabilization of oxides by solid-liquidelectron interactions remains an important challenge. In this work we present a methodology to assess LP-TEM oxide stability in an aqueous phase, by subjecting several oxides of technological importance to a controlled electron dose in water. We show a correlation based on the Gibbs free energy of oxide hydration that can be used to assess the stability of oxides and demonstrate the existence of several remarkably stable oxides, with no observable structural changes after one hour of electron beam irradiation in LP-TEM. Rationalizing such destabilization phenomena combined with the identification of stable oxides allows for designing LP-TEM experiments free from adverse beam effects and thus investigations of numerous relevant nanoscale processes in water.
\end{abstract}

\section{KEYWORDS}

liquid phase transmission electron microscopy (LP-TEM), transmission electron microscopy, electron beam damage, metal oxide nanomaterials, oxide stability

\section{Introduction}

Since time immemorial, oxides have been incredibly important materials in a wide variety of applications, from ancient pottery to modern superconductors. Industrial applications include heterogeneous catalysts, where nanoparticle oxides are often used as support or catalyst [1-4], structural and refractory ceramics such as bricks or concrete [5], or semiconductors [6,7], adsorbents [8], superconductors [9], and protective coatings [10].

Properties and performance of oxides in many of these applications are dictated by nanometer scale structural features. Influence of the catalyst nanoparticle size [11], morphology [12] and nanoparticlesupport interactions $[4,13]$ on catalyst activity, selectivity and stability, the morphology and nature of nanoscale defects on corrosion $[14,15]$, or the presence of nanometer-sized defects in oxide boundary layers on semiconductor performance [16] are all important examples of how nanoscale features can influence overall oxide behavior.

Transmission electron microscopy (TEM) has been an indispensable tool to this end, allowing visualization of nanoscale morphology and atomic structure of a variety of oxide materials [17-19]. However, due to the high vacuum conditions under which TEM is operated, studies were limited to dry samples, which excludes the option to investigate the material during its formation or subsequent application. In recent years, the development of technologies for in situ heating [20], gas [21-25] and in particular liquid [26-28] TEM measurements has expanded the possibilities for characterization of nanomaterials and nanoscale processes dramatically.

Liquid phase TEM (LP-TEM) is particularly relevant to studying the formation of nanoscale oxide systems, such as nanoparticle nucleation and growth, as many of these processes take place in a liquid. Furthermore, LP-TEM also allows the study of the liquid-based processes involving oxide materials. For example, in catalyst synthesis [29], often small metal or metal oxide nanoparticles are deposited on a thermally stable and high surface area oxide, such as $\mathrm{Al}_{2} \mathrm{O}_{3}$ or $\mathrm{SiO}_{2}$, in a liquid phase. Knowledge of the nanoscale processes involved in such syntheses is incomplete, limiting thus our ability to control the catalyst structure [4]. Despite the massive body of work on catalyst synthesis and a large variety of preparation methods, this lack of fundamental knowledge results in catalyst preparation often being considered more of an art rather than a science [30]. Furthermore, stability of catalysts in liquid phase reactions, in particular for biomass conversion $[31,32]$, is highly important, but still poorly understood. Other processes of significant interest are metal corrosion [33] and battery assembly and operation [34]. These fields, among many others, could therefore greatly benefit from the application of LP-TEM.

The most popular method to perform LP-TEM experiments is by utilizing the closed cell design [35], which encloses the sample and liquid between two silicon chips with silicon nitride windows in a dedicated holder, although enclosing liquids between two graphene layers $[36,37]$ or differential aperture pumping techniques have also been reported [38]. The closed cell technique has already been employed to study nanoscale dynamic processes such as biomineralization $[39,40]$, carbon nanotube degradation by macrophages [41], nanoparticle movement and interactions [42, 43], and electrochemical deposition and growth $[44,45]$.

The majority of the published articles still highlight an important challenge in LP-TEM though, which is distinguishing electron beam induced effects from the phenomena under investigation. Along with the beam damage mechanisms already known from conventional TEM imaging in a vacuum, LP-TEM additionally suffers effects originating from interactions of the electron beam with the liquid. The main result of these interactions is radiolysis of the liquid and 
the subsequent formation of radicals and other reactive chemical species which can locally alter liquid chemistry [46]. This beam induced effect can be and has been used to initiate and drive nanoscale processes, such as nucleation and growth of nanoparticles $[47,48]$. However, it is mostly considered detrimental to the process under investigation, as it was shown to significantly alter the structure or even lead to dissolution of the materials under investigation [49].

Although this effect is well-known for biological and carbonaceous samples [50], most LP-TEM studies so far have focused on metal nanoparticles, while the understanding of oxide degradation behavior is still limited. Recent investigations on iron (hydr)oxide [51] and silicon dioxide [52-54] have shown that oxide materials can also suffer from electron beam induced destabilization in a liquid environment. In addition, Lu et al. [55] investigated dissolution behavior of several oxides in LP-TEM. They observed a significant increase in dissolution rate of the oxides in the presence of the electron beam, which was attributed to the electron beam induced formation of oxygen vacancies. However, they also observed significant variations in stability and dissolution rate between the oxides, which could not be fully explained by this mechanism.

In view of growing interest in using LP-TEM to study oxide materials, it is of vital importance to improve our understanding of these degradation phenomena and to devise methodologies to suppress them. The goal of our study was to systematically investigate the factors contributing to oxide destabilization in LP-TEM, for which we selected six technologically important and widely used oxides, namely silica, alumina, magnesia, titania, niobia and zirconia. The stability of oxides imaged in an LP-TEM environment ranged from fully stable ones to those that dissolve within minutes of exposure to the electron beam. We discovered that the oxide stability directly correlates with the extent to which the formation of the respective hydroxide is thermodynamically favored. This correlation is an excellent requisite that will aid in predicting the behavior of oxides during LP-TEM experiments. Furthermore, it can be used to select suitable oxides, i.e. those not affected by electron beam and water, for LP-TEM studies of nanoscale processes in water.

\section{Results}

\subsection{Materials characterization}

For this study we have selected $\mathrm{SiO}_{2}, \mathrm{Al}_{2} \mathrm{O}_{3}, \mathrm{MgO}, \mathrm{TiO}_{2}, \mathrm{ZrO}_{2}$ and $\mathrm{Nb}_{2} \mathrm{O}_{5}$. Before introducing them to liquid phase transmission electron microscopy and studying their stability and behavior, we performed a study of their bulk physicochemical properties. Table 1 summarizes the main properties of the oxides used in this work.

In nitrogen physisorption the $\mathrm{MgO}$ and calcined $\mathrm{Nb}_{2} \mathrm{O}_{5}\left(\mathrm{c}-\mathrm{Nb}_{2} \mathrm{O}_{5}\right)$ samples exhibited a type II $\mathrm{N}_{2}$ sorption isotherm (Figs. S1(c) and S1(h) in the Electronic Supplementary Material (ESM)), indicating a macroporous (pores $>50 \mathrm{~nm}$ ) morphology. For the other oxides, a type IV isotherm was observed, indicating the presence of mesoporosity (2-50 nm pores) (Fig. S1 in the ESM). For all mesoporous oxides, a $\mathrm{H}_{3}$ type of hysteresis was observed, usually associated with non-rigid aggregates of primary particles [56] and often indicative of non-spherical particles. Except for the case of the amorphous $\mathrm{TiO}_{2}$, the oxides did not display significant microporosity (pores $<2 \mathrm{~nm}$ ). Specific surface areas varied significantly between the oxides, from $9 \mathrm{~m}^{2} \cdot \mathrm{g}^{-1}$ for $\mathrm{c}-\mathrm{Nb}_{2} \mathrm{O}_{5}$ to almost $300 \mathrm{~m}^{2} \cdot \mathrm{g}^{-1}$ for the amorphous $\mathrm{TiO}_{2}$ sample. Pore volumes also varied, from $<0.1 \mathrm{~mL} \cdot \mathrm{g}^{-1}$ for the $\mathrm{MgO}$ and $\mathrm{c}-\mathrm{Nb}_{2} \mathrm{O}_{5}$ to $0.44 \mathrm{~mL} \cdot \mathrm{g}^{-1}$ for the $\mathrm{Al}_{2} \mathrm{O}_{3}$.

TEM supported these observations, as can be observed in Fig. 1, with all of the materials consisting of agglomerates of nanoparticles, albeit with different primary particle size. In the case of $\mathrm{MgO}$ and c- $\mathrm{Nb}_{2} \mathrm{O}_{5}$ (Figs. $1(\mathrm{c})$ and $1(\mathrm{~h})$ ), the primary particles were too large for any significant capillary condensation to take place in the
Table 1 Summary of the characterization results for all oxides used in this research

\begin{tabular}{|c|c|c|c|c|c|}
\hline Oxide & $\begin{array}{c}\text { BET } \\
\text { surface } \\
\text { area } \\
\left(\mathrm{m}^{2} \cdot \mathrm{g}^{-1}\right)\end{array}$ & $\begin{array}{l}\text { Total pore } \\
\text { volume } \\
\left(\mathrm{cm}^{3} \cdot \mathrm{g}^{-1}\right)\end{array}$ & $\begin{array}{l}\text { TGA total } \\
\text { mass loss } \\
\text { (\% of } \\
\text { initial) }\end{array}$ & $\begin{array}{l}\text { MS species } \\
\text { detected }(-)\end{array}$ & $\begin{array}{l}\text { XRD crystal } \\
\text { structures } \\
(-)\end{array}$ \\
\hline Stöber $\mathrm{SiO}_{2}$ & 49 & 0.38 & 0.4 & - & Amorphous \\
\hline $\begin{array}{l}\text { Puralox } \\
\mathrm{Al}_{2} \mathrm{O}_{3}\end{array}$ & 145 & 0.44 & 5.0 & $\mathrm{H}_{2} \mathrm{O}, \mathrm{CO}_{2}$ & $\begin{array}{c}F d \overline{3} m \\
\left(\gamma-\mathrm{Al}_{2} \mathrm{O}_{3}\right)\end{array}$ \\
\hline $\mathrm{MgO}$ & 22 & 0.01 & 3.1 & $\mathrm{CO}_{2}$ & $\begin{array}{c}F m \overline{3} m \\
\text { (periclase) }\end{array}$ \\
\hline $\mathrm{ZrO}_{2}$ & 97 & 0.25 & 2.7 & $\mathrm{H}_{2} \mathrm{O}, \mathrm{CO}_{2}$ & $\begin{array}{c}P 2_{1} / c \\
\text { (Baddeleyite) }\end{array}$ \\
\hline $\mathrm{P} 25 \mathrm{TiO}_{2}$ & 45 & 0.16 & -1.3 & - & $\begin{array}{c}P 42 / m n m \\
\text { (rutile) } \\
\text { I4 } 1 \text { /amd } \\
\text { (anatase) }\end{array}$ \\
\hline $\begin{array}{c}\text { Amorphous } \\
\mathrm{TiO}_{2}\end{array}$ & 292 & 0.28 & 16.0 & $\mathrm{H}_{2} \mathrm{O}$ & Amorphous \\
\hline Niobic acid & 155 & 0.18 & 12.5 & $\mathrm{H}_{2} \mathrm{O}$ & Amorphous \\
\hline $\begin{array}{c}\text { Calcined } \\
\mathrm{Nb}_{2} \mathrm{O}_{5}\end{array}$ & 9 & 0.04 & -0.1 & - & $\begin{array}{c}P 2 / m \\
\left(\mathrm{H}-\mathrm{Nb}_{2} \mathrm{O}_{5}\right)\end{array}$ \\
\hline
\end{tabular}

${ }^{\mathrm{a}}$ From nitrogen physisorption at $p / p_{0}=0.9$.

interparticle space during $\mathrm{N}_{2}$ physisorption, explaining the lack of hysteresis in the isotherm and lack of mesoporosity observed. The other oxides had significantly smaller primary particle sizes, often non-spherical, leading to the presence of interparticle mesoporosity, and thus occurrence of capillary condensation. In the case of niobic acid, intraparticle mesopores of about $5 \mathrm{~nm}$ were present next to the interparticle mesoporosity, as highlighted in the magnified part of Fig. 1(g) and reported before [57]. In the case of amorphous $\mathrm{TiO}_{2}$ the primary particle size was only a few $\mathrm{nm}$, giving rise to micropores in addition to the mesopores, as can be observed in the magnified part of Fig. 1(e). Furthermore, the oxides with the smaller primary particle size, as expected, displayed larger BrunauerEmmett-Teller (BET) specific surface area.

$\mathrm{X}$-ray diffractograms of the oxides (summarized in Table 1 and Fig. S2 in the ESM) confirmed that the oxides are present in the expected crystal structures and that the amorphous $\mathrm{TiO}_{2}$, Stöber $\mathrm{SiO}_{2}$ and niobic acid are indeed non-crystalline.

Finally, thermogravimetric analysis (TGA) coupled with mass spectrometry (MS) in an $\mathrm{O}_{2} / \mathrm{Ar}$ atmosphere (summarized in Table 1 and Fig. S3 in the ESM) showed that several oxides still contained water, which was expected and poses no problem for the LP-TEM experiments which take place in $\mathrm{H}_{2} \mathrm{O}$. The commercial $\mathrm{MgO}, \mathrm{Al}_{2} \mathrm{O}_{3}$ and $\mathrm{ZrO}_{2}$ powders released also significant amounts of $\mathrm{CO}_{2}$. In the case of $\mathrm{MgO}$, this can be attributed to adsorption of carbon dioxide from air leading to formation of a surface carbonate, which is a well-known phenomenon for this oxide [58]. The most significant mass loss and $\mathrm{CO}_{2} \mathrm{MS}$ signal was also observed at the expected decomposition temperature for $\mathrm{MgCO}_{3}$ at approximately $350{ }^{\circ} \mathrm{C}$, indicating that the origin of the observed $\mathrm{CO}_{2}$ is likely from a $\mathrm{MgCO}_{3}$ surface carbonate. For the $\mathrm{ZrO}_{2}$ and $\mathrm{Al}_{2} \mathrm{O}_{3}$, this $\mathrm{CO}_{2}$ probably originated from the preparation method that might have involved the use of metal alkoxides.

\subsection{Liquid phase transmission electron microscopy}

The stability and behavior of all aforementioned oxides in LP-TEM was investigated. While detailed explanation of preparation and imaging conditions can be found in the Methods section, it is important to note that oxides as received or synthesized were placed in an LP-TEM cell containing water and that imaging was performed in scanning TEM (STEM) mode whereby a focused beam of electrons is raster scanned across the field of view. 
(a) $\mathrm{SiO}_{2}$

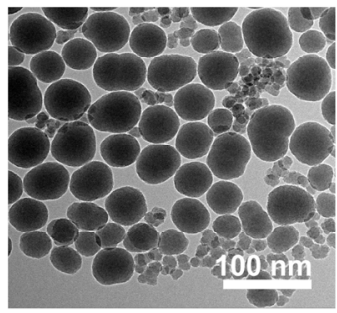

(e) Amorphous $\mathrm{TiO}_{2}$

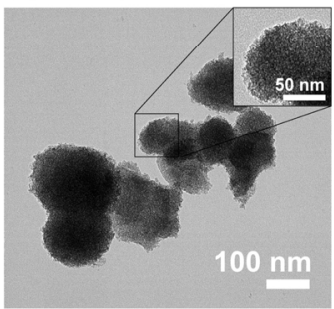

(b) $\mathrm{Al}_{2} \mathrm{O}_{3}$

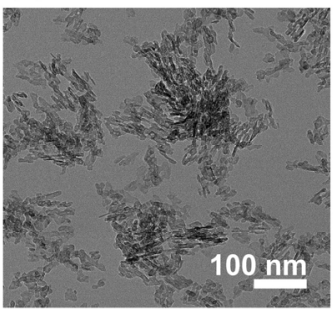

(f) $\mathrm{P}_{25} \mathrm{TiO}_{2}$

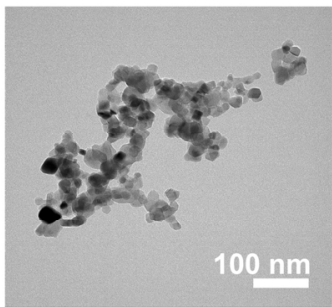

(c) $\mathrm{MgO}$

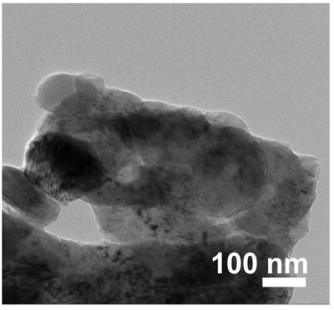

(g) Niobic acid

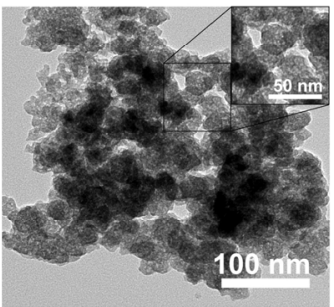

(d) $\mathrm{ZrO}_{2}$

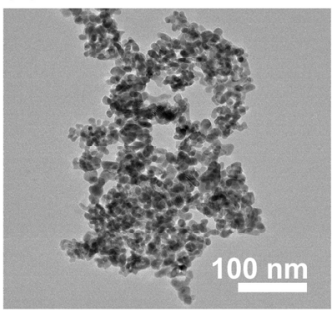

(h) Calcined $\mathrm{Nb}_{2} \mathrm{O}_{5}$

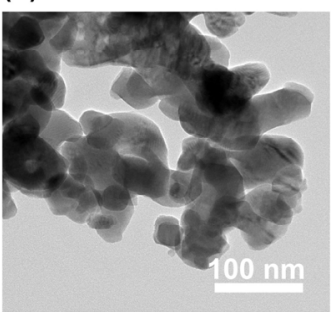

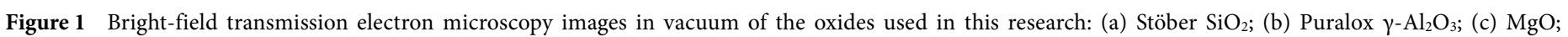
(d) $\mathrm{ZrO}_{2}$; (e) amorphous $\mathrm{TiO}_{2}$, with the primary particles visible in the inset; (f) $\mathrm{P} 25 \mathrm{TiO}_{2}$ with some dark regions due to diffraction contrast; (g) niobic acid, with $\sim 5 \mathrm{~nm}$ mesopores visible in the inset; (h) calcined $\mathrm{Nb}_{2} \mathrm{O}_{5}$.

Imaging metal and metal oxide nanoparticles in liquid environment with the spread parallel (TEM) electron beam has been shown to lead to dissolution and degradation of the material under investigation, while imaging with scanning electron beam (STEM) also introduced shape changes associated with the scanning direction of the beam [52]. As a control experiment, a sample of each oxide was also subjected to continuous electron beam scanning in high vacuum, using a comparable or slightly higher cumulative electron dose and electron dose rate $\left(1.9 \times 10^{7} \mathrm{e}^{-} \cdot \mathrm{nm}^{-2}\right.$ and $5.2 \times 10^{3} \mathrm{e}^{-} \cdot \mathrm{nm}^{-2} \cdot \mathrm{s}^{-1}$, respectively, for the vacuum experiments). Apart from carbon contamination depositing during scanning of some samples, in particular the $\mathrm{SiO}_{2}$ and $\mathrm{P} 25 \mathrm{TiO}_{2}$ samples, no changes in particle morphology were observed for any of the oxides during these experiments (Fig. S4 in the ESM).

(a)
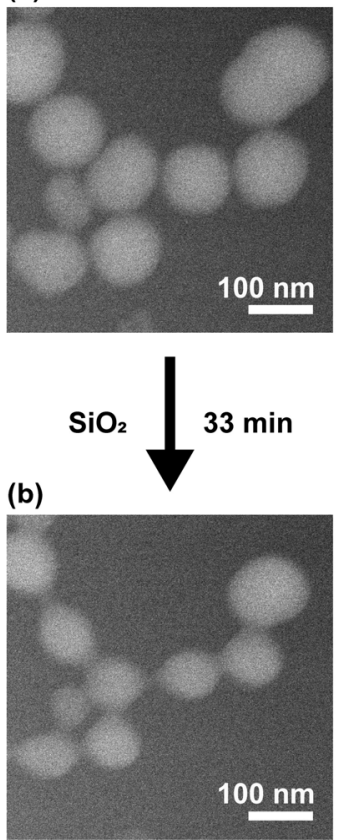

In LP-TEM however, shape and size changes were apparent and occurred to varying degrees, indicating that the overall stability was markedly different between the studied oxides, as illustrated in Fig. 2, Fig. S5 and the Movies ESM1-ESM4 in the ESM. As reported previously [52], spherical $\mathrm{SiO}_{2}$ nanoparticles significantly elongated along the scanning direction of the electron beam and lost material during this process; when changing the scanning direction, the particle elongation changed accordingly (Figs. 2(a) and 2(b), Movie ESM1, Fig. S5(a) in the ESM).

$\mathrm{Al}_{2} \mathrm{O}_{3}$ and $\mathrm{MgO}$ on the other hand did not show this elongation behavior (Figs. 2(c)-2(f), Movies ESM1 and ESM2, Figs. S5(b) and S5(c) in the ESM), but did dissolve significantly faster than the silica. Although reduced in size, $\mathrm{SiO}_{2}$ particles were still present after $33 \mathrm{~min}$ of scanning, while for both $\mathrm{Al}_{2} \mathrm{O}_{3}$ and $\mathrm{MgO}$ no material could be (c)

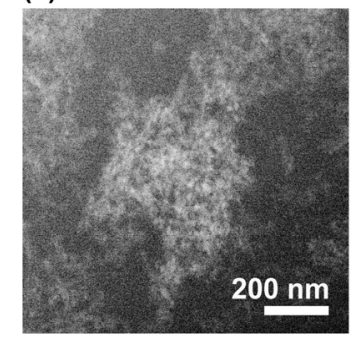

(e)

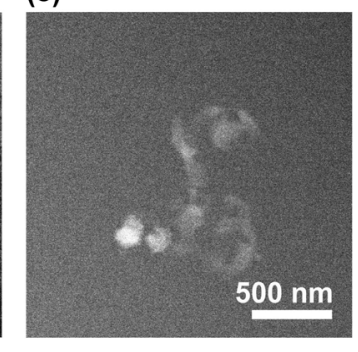

(d)
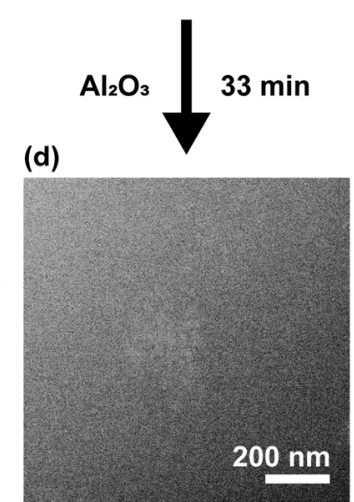

(f)
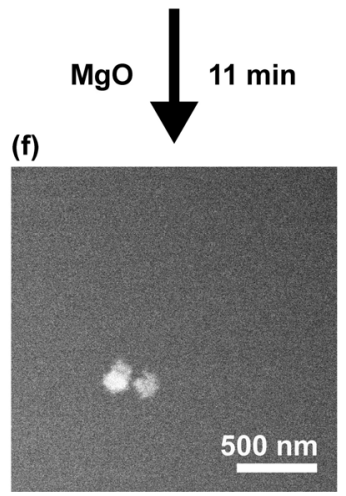

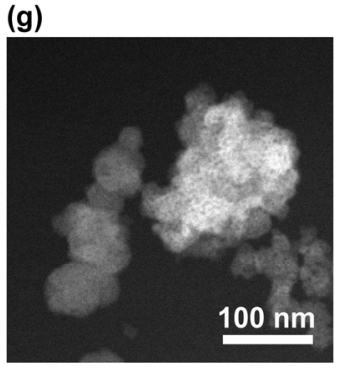

(g)

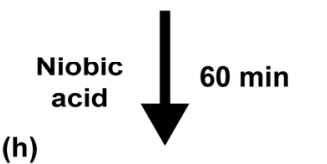

(h)

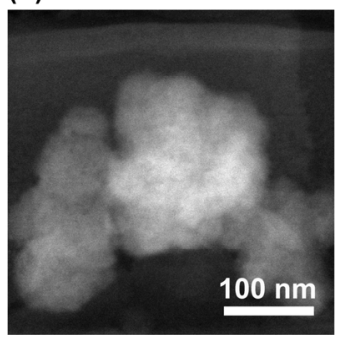

Figure 2 Overview of LP-TEM behavior of the studied oxides with low stability. (a) and (b) Stöber $\mathrm{SiO}_{2}$ before and after 33 min of imaging (dose rate: $\left.5.2 \mathrm{E}+03 \mathrm{e}^{-} \cdot \mathrm{nm}{ }^{-2} \cdot \mathrm{s}^{-1}\right)$; (c) and (d) $\gamma-\mathrm{Al}_{2} \mathrm{O}_{3}$ before and after 33 min of imaging (dose rate: $1.3 \mathrm{E}+03 \mathrm{e}^{-} \cdot \mathrm{nm}^{-2} \cdot \mathrm{s}^{-1}$ ); (e) and (f) $\mathrm{MgO}$ before and after 11 min of imaging, with some $\mathrm{ZrO}{ }_{2}$ contamination (two bright particles in the lower left corner of the agglomerate) (dose rate: $\left.3.3 \mathrm{E}+02 \mathrm{e}^{-} \cdot \mathrm{nm}^{-2} \cdot \mathrm{s}^{-1}\right)$; $(\mathrm{g})$ and (h) niobic acid before and after 60 min of imaging (dose rate: $1.0 \mathrm{E}+04 \mathrm{e}^{-} \cdot \mathrm{nm}^{-2} \cdot \mathrm{s}^{-1}$ ). 
detected already after 12 and 2 min respectively, for the highest dose rates used, even though the dose rate for the $\mathrm{Al}_{2} \mathrm{O}_{3}$ was comparable and significantly lower for the $\mathrm{MgO}$ (details on dose rates are available in the methods and Tables $\mathrm{S} 1-\mathrm{S} 3$ in the ESM for the $\mathrm{SiO}_{2}, \mathrm{Al}_{2} \mathrm{O}_{3}$ and $\mathrm{MgO}$, respectively). In the case of $\mathrm{Al}_{2} \mathrm{O}_{3}$, two stages can be distinguished (see Movie ESM2 and Fig. S5(b) in the ESM). In the initial stage the contrast between particle and liquid decreased a lot, indicating thinning in the direction of the beam as contrast in these experiments is mainly governed by the atomic number of the elements and the aluminum oxide particle thickness. During the second stage, the particles decreased in size, but interestingly, the shape remained unchanged. For $\mathrm{MgO}$, particles tended to move during imaging despite initially being fixed to the window of the LP-TEM cell, and they dissolved even more quickly than the alumina (Figs. 2(e) and 2(f), Fig. S5(c) and Movie ESM3 in the ESM). It was therefore challenging to evaluate contrast differences. Both shape changes and reduction in size were observed, but appeared not to be correlated with the electron beam scanning direction.

A semi-quantification of the oxide volume at different time during the experiment has also been performed based on the respective TEM images. The volume of the material in the field of view was estimated by measuring particle length and width of all particles present in the image and assuming perfectly spheroidal particles in the case of $\mathrm{SiO}_{2}$ and $\mathrm{MgO}$.

In the case of $\mathrm{Al}_{2} \mathrm{O}_{3}$, volume was determined by assuming a linear relationship between pixel intensity and alumina thickness and subsequently integrating over the entire image. Volume loss for the individual experiments has been summarized in Tables S1-S3 in the ESM.

For each of these three oxides, the volume as a function of time of a representative experiment has also been plotted in Fig. 3. This clearly illustrates the large differences in stability between these oxides, with $\mathrm{MgO}$ losing far more volume than $\mathrm{Al}_{2} \mathrm{O}_{3}$ or $\mathrm{SiO}_{2}$, even though the electron beam current was the same in all experiments.

For niobic acid, the behavior in LP-TEM was very different from the previous three oxides (Figs. 2(g) and 2(h), Fig. S5(d) and Movie ESM4 in the ESM). Instead of reducing in size, the particles seemed to grow or swell and became more rounded, while the mesopores of $\sim 5 \mathrm{~nm}$ disappeared over time. The contrast also decreased, indicating thinning in the direction of the electron beam. This could originate from the oxide particles slowly collapsing and spreading on the surface of the $\mathrm{Si}_{x} \mathrm{~N}_{y}$ window. All of the observed effects occurred much slower than in the previous three oxides, with imaging time reaching $60 \mathrm{~min}$ without niobic acid dissolving and disappearing, using a dose rate of $5.2 \times 10^{3} \mathrm{e}^{-} \cdot \mathrm{nm}^{-2} \cdot \mathrm{s}^{-1}$.

Surprisingly, the $c-\mathrm{Nb}_{2} \mathrm{O}_{5}, \mathrm{ZrO}_{2}$, amorphous $\mathrm{TiO}_{2}$ and $\mathrm{P} 25 \mathrm{TiO}_{2}$ oxides appeared to be highly stable under these LP-TEM imaging

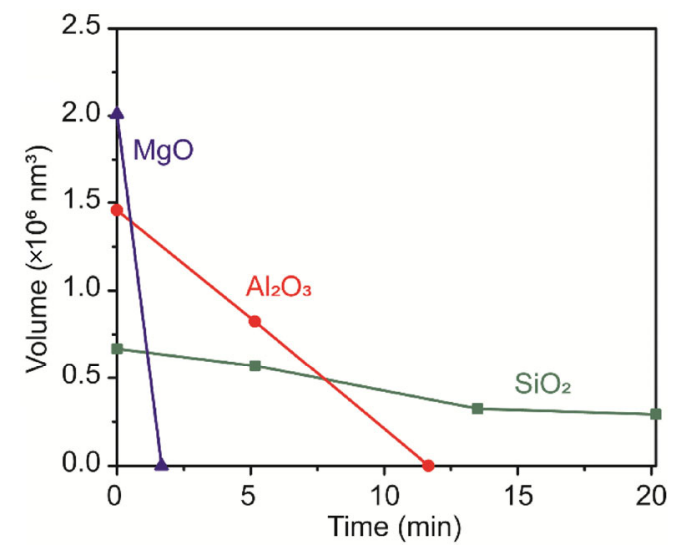

Figure 3 A representative experiment of each oxide of low stability, except niobic acid, following their volume in $\mathrm{nm}^{3}$ over time, all with an electron beam current of $0.21 \mathrm{nA}\left(1.3 \mathrm{E}+9 \mathrm{e}^{-} \cdot \mathrm{s}^{-1}\right)$. conditions, as illustrated in Fig. 4, Fig. S6 and Movies ESM5-ESM8 in the ESM. Apart from some movement during imaging, no significant changes in shape, size or contrast were observed for any of these oxides, even after 60 min of imaging with a dose rate of $5.2 \times$ $10^{3} \mathrm{e}^{-} \cdot \mathrm{nm}^{-2} \cdot \mathrm{s}^{-1}$. However, the $\mathrm{P} 25 \mathrm{TiO}_{2}, \mathrm{ZrO}_{2}$ and $\mathrm{c}-\mathrm{Nb}_{2} \mathrm{O}_{5}$ showed an interesting "flashing" phenomenon involving the occasional formation, growth and disappearance of very bright spots at the surface of the oxide, as can be observed in the Movies ESM5, ESM6 and ESM8 and a still-frame depicting one such bright spot in Fig. 4(g). Such a phenomenon was not observed in the case of the amorphous $\mathrm{TiO}_{2}$ or any of the less stable oxides from Fig. 2. Although not fully understood yet, this "flashing" is tentatively ascribed to a local charging of the sample, which can result in changes in the deflection angle of electrons passing through the sample $[17,59]$.

\section{Discussion}

As demonstrated with LP-TEM, oxides which are generally stable in aqueous environments at neutral or mildly acidic $\mathrm{pH}$ [60] can exhibit large differences in stability when irradiated with electrons in an aqueous environment. Some oxides degraded rapidly, while others remained stable during one hour of continuous imaging. Furthermore, all oxides were proven to be stable when either the electron beam or the water is absent, highlighting the detrimental effect of combining electron beam and water.

To understand the origin of these differences in stability in LP-TEM, we first consider some of the major physicochemical properties that are known to influence oxide stability in water (Tables 1 and 2). First such is solubility at neutral or mildly acidic $\mathrm{pH}$, as calculations indicate that electron beam induced water radiolysis produces, among other species, a significant number of hydronium ions $\left(\mathrm{H}_{3} \mathrm{O}^{+}{ }_{(\mathrm{aq})}\right)$ and solvated electrons $\left(\mathrm{e}^{-}{ }_{(\mathrm{aq})}\right)$. This results in a local decrease in $\mathrm{pH}$ to approximately $4-5$, depending on the intensity of the ionizing radiation [61]. The solubility under these conditions varies between the oxides studied here and ranges from $2.5 \times 10^{-12}$ $\mathrm{mol} \cdot \mathrm{L}^{-1}$ for zirconia to $1.6 \times 10^{-3} \mathrm{~mol} \cdot \mathrm{L}^{-1}$ for silica, as summarized in Table 2. Although the oxides that appeared stable in LP-TEM also have a very low solubility, the oxide with the highest solubility of all is $\mathrm{SiO}_{2}$, which proved to be much more stable than either $\mathrm{Al}_{2} \mathrm{O}_{3}$ or $\mathrm{MgO}$, both of which exhibit lower solubility than $\mathrm{SiO}_{2}$. Furthermore, it has been argued that in aqueous environments subjected to intense ionizing radiation, local supersaturation could be present [55], suggesting that solubility is not the major cause for the observed differences in stability.

Second, morphological differences, including surface area, porosity and particle morphology vary widely between the studied oxides (Table 1). Specific surface area in particular could be considered as a potential cause of difference in the stability, since it relates to the contact area between liquid and oxide, allowing for more interaction. However, no clear correlation was found between any of the textural properties and oxide stability either. Comparing for example $\mathrm{SiO}_{2}$, $\mathrm{Al}_{2} \mathrm{O}_{3}$ and $\mathrm{MgO}$, with $\mathrm{MgO}$ having the lowest specific surface area of these oxides and $\mathrm{Al}_{2} \mathrm{O}_{3}$ the highest, both were less stable than $\mathrm{SiO}_{2}$, demonstrating that surface area does not seem to dominate stability.

Third, crystallinity and residual water content does not seem to affect the stability of $\mathrm{TiO}_{2}$, but interestingly, it did relate to an effect on the stability of niobia, with the amorphous and hydrated niobic acid not being completely stable, as opposed to the crystalline $\mathrm{Nb}_{2} \mathrm{O}_{5}$. The main difference between niobic acid and calcined niobia is that water forms significantly stronger bonds in the former than in the latter [68], to the extent that niobic acid is a highly acidic oxide. In the completely stable amorphous $\mathrm{TiO}_{2}$ on the other hand, even though it is also a precipitated form of a relatively ill-defined and non-calcined oxide, the water does not form similar strong bonds. 
(a)
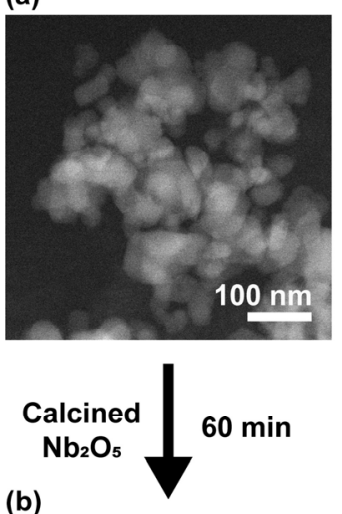

(b)

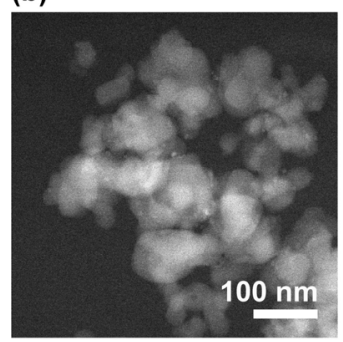

(c)

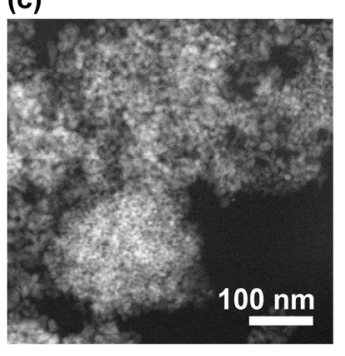

(d)
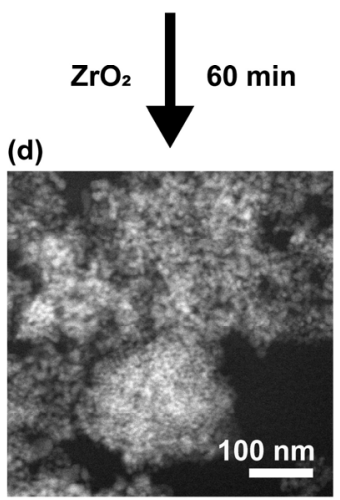

(e)
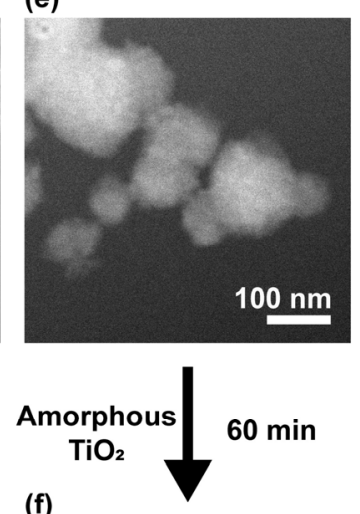

(f)

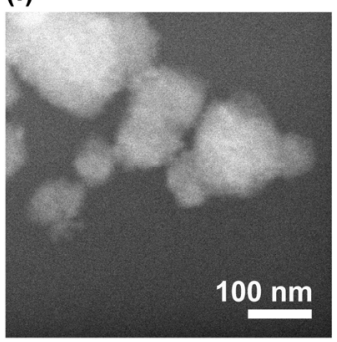

(g)

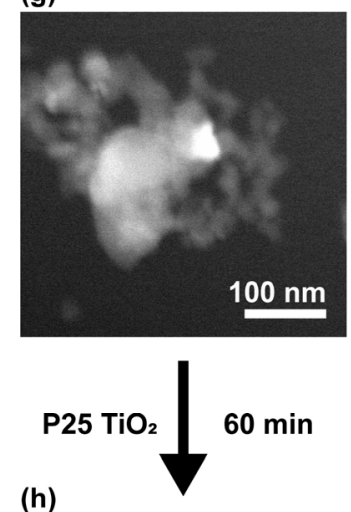

(h)

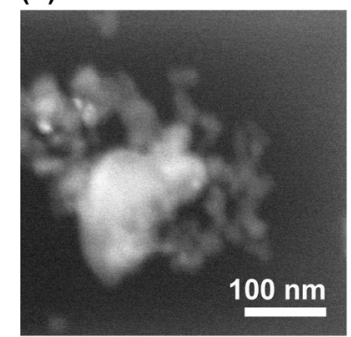

Figure 4 Overview of LP-TEM behavior for the stable oxides. (a) and (b) Calcined $\mathrm{Nb}_{2} \mathrm{O}_{5}$ before and after 60 min of imaging. (c) and (d) $\mathrm{ZrO}_{2}$ before and after 60 min of imaging. (e) and (f) Amorphous $\mathrm{TiO}_{2}$ before and after 60 min of imaging. (g) and (h) $\mathrm{P}_{25} \mathrm{TiO}_{2}$ before and after 60 min of imaging. The dose rate in each experiment was $5.2 \mathrm{E}+03 \mathrm{e}^{-} \cdot \mathrm{nm}^{-2} \cdot \mathrm{s}^{-1}$, except for the $\mathrm{P} 25 \mathrm{TiO}_{2}$, in which the dose rate was $1.0 \mathrm{E}+04 \mathrm{e}^{-} \cdot \mathrm{nm}^{-2} \cdot \mathrm{s}^{-1}$.

Table 2 Solubility and standard Gibbs free energy for reaction 1 per mole of metal (M) for various oxides

\begin{tabular}{cccc}
\hline Oxide & $\begin{array}{c}\text { Solubility in } \mathrm{H}_{2} \mathrm{O} \\
\left(\mathrm{mol}_{\text {metal }} \cdot \mathrm{L}^{-1}\right)\end{array}$ & $\begin{array}{c}\Delta G^{0} \text { Hydration } \\
\left(\mathrm{kJ} \cdot \text { mol }_{\text {metal }}{ }^{-1}\right)\end{array}$ & References \\
\hline${\text { Amorphous } \mathrm{SiO}_{2}}$ & $1.6 \mathrm{E}-03$ & -8.0 & {$[60,62,63]$} \\
$\gamma-\mathrm{Al}_{2} \mathrm{O}_{3}$ & $1.6 \mathrm{E}-08$ & -18 & {$[62-64]$} \\
$\mathrm{MgO}$ & $1.8 \mathrm{E}-04$ & -27 & {$[62-64]$} \\
$\mathrm{Nb}_{2} \mathrm{O}_{5}$ & $2.5 \mathrm{E}-08$ & 52 & {$[60,65]$} \\
$\mathrm{TiO}_{2}$ & $1.0 \mathrm{E}-09$ & 46 & {$[62,66]$} \\
$\mathrm{Ti}_{2} \mathrm{O}_{3}$ & - & 16 & {$[62-64]$} \\
$\mathrm{TiO}$ & - & 34 & {$[62-64]$} \\
$\mathrm{ZrO}_{2}$ & $2.5 \mathrm{E}-12$ & 30 & {$[62-64]$} \\
$\mathrm{CeO}_{2}$ & - & 110 & {$[60]$} \\
$\mathrm{Ce}_{2} \mathrm{O}_{3}$ & $1.6 \mathrm{E}-06$ & -59 & {$[60,64,67]$} \\
$\mathrm{CuO}$ & $2.0 \mathrm{E}-10$ & 13 & {$[62-64]$} \\
$\mathrm{Cu}_{2} \mathrm{O}$ & - & -63 & {$[60,62-64]$} \\
$\mathrm{Fe}_{2} \mathrm{O}_{3}$ & $4.0 \mathrm{E}-12$ & 12 & {$[62-64]$} \\
$\mathrm{FeO}$ & $3.2 \mathrm{E}-10$ & -6.6 & {$[62-64]$} \\
\hline
\end{tabular}

This indicates that chemical bond formation of water with the oxide is of significant importance to the stability of the oxides. To confirm this hypothesis, we compared the thermodynamic driving force for the formation of the hydroxide from the oxide in water (Reaction (1)), that is, the Gibbs free energy for the hydration reaction $\left(\Delta G_{\mathrm{H}}^{0}\right)$ of the investigated oxides.

$$
1 / x \mathrm{M}_{x} \mathrm{O}_{y}(\mathrm{~s})+y / x \mathrm{H}_{2} \mathrm{O}(\mathrm{l}) \rightleftharpoons \mathrm{M}(\mathrm{OH})_{2 y / x}(\mathrm{~s})
$$

Figure 5 clearly illustrates the correlation between oxide stability and the $\Delta G^{0}{ }_{\mathrm{H}}$ (values listed in Table 2), with all stable oxides having a positive $\Delta G^{0} \mathrm{H}$, favoring the oxide over the hydroxide. On the other hand, the $\Delta G_{\mathrm{H}}^{0}$ is negative for the unstable oxides, favoring the hydroxide. As a semi-quantitative measure of (in)stability of the $\mathrm{SiO}_{2}, \mathrm{Al}_{2} \mathrm{O}_{3}$ and $\mathrm{MgO}$, the number of electrons required to remove a single atom from the oxide was calculated by determining the number of removed atoms based on the volume that has been removed from

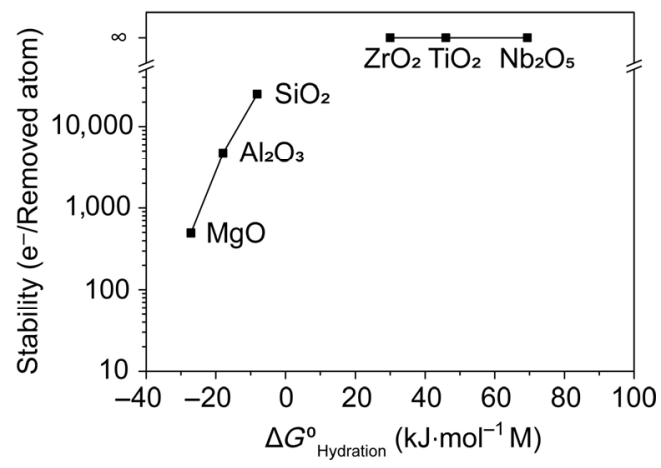

Figure 5 Comparison of the stability of the oxides used in this research under the prevailing conditions of LP-TEM experiments as a function of the Gibbs free energy of formation of the solid hydroxide from the respective oxide (hydration energy), with stability defined as the number of electrons required to remove a single atom (both the oxygen and metal atoms) from the material.

the oxide, approximating particle geometry and assuming bulk densities, and the number of electrons the area has been exposed to. The dose rate, volume reduction and values for the electrons required to remove a single atom for each of the individual experiments are listed in Tables $\mathrm{S} 1-\mathrm{S} 3$ in the $\mathrm{ESM}$ for $\mathrm{SiO}_{2}, \mathrm{Al}_{2} \mathrm{O}_{3}$ and $\mathrm{MgO}$, respectively. Due to the difficulty of assessing the instability of the niobic acid and the lack of thermodynamic data, quantification was not possible for this sample. The semi-quantification shows that the severity of electron beam induced oxide degradation correlates with the favorability of hydroxide formation. For oxides with a more negative value of $\Delta G^{0}$ (e.g. $\mathrm{MgO}$ vs. $\mathrm{SiO}_{2}$ ), far fewer electrons are required to remove an atom from the oxide.

Although dose rate $\left(\mathrm{e}^{-} \cdot \mathrm{nm}^{-2} \cdot \mathrm{s}^{-1}\right)$ has been shown to sometimes influence the observed phenomena in liquid cell [69], variation thereof in these experiments did not show any significant differences in the amount of electrons required to remove an atom. This is also observed when comparing the resulting values for electrons required per removed atom for the $\mathrm{Al}_{2} \mathrm{O}_{3}$ and $\mathrm{MgO}$ experiments performed at different magnifications, as listed in Tables S2 and S3 in the ESM. Therefore, the required lower magnifications and hence lower dose 
rates in the case of $\mathrm{Al}_{2} \mathrm{O}_{3}$ and $\mathrm{MgO}$, necessary to image long enough to observe the degradation in sufficient detail, did not influence the comparison to any significant extent.

Another difference between the stable and unstable oxides in this study is that the stable oxides are all reducible, relatively easily releasing oxygen atoms, which could also be used to explain these observations. However, a recent study showed that $\mathrm{Fe}_{2} \mathrm{O}_{3}, \mathrm{CeO}_{2}$ and $\mathrm{CuO}$, which are also reducible oxides, were unstable under electron beam irradiation in the presence of water [55]. Seeing that these three oxides also have a positive $\Delta G_{\mathrm{H}}^{0}$, according to our hypothesis they should be stable. However, because they are easily reducible, it is important to also consider their sub-oxides such as $\mathrm{Cu}_{2} \mathrm{O}, \mathrm{FeO}$ and $\mathrm{Ce}_{2} \mathrm{O}_{3}$. As can be seen in Table 2, these sub-oxides actually have a negative $\Delta G^{0}$. This is also in agreement with the observations of $\mathrm{Lu}$ et al. [55], in which they report that electron beam induced dissolution of cerium oxide becomes extremely fast only after the $\mathrm{Ce}_{2} \mathrm{O}_{3}$ phase is observed. The sub-oxides of $\mathrm{TiO}_{2}\left(\mathrm{Ti}_{2} \mathrm{O}_{3}\right.$ and $\left.\mathrm{TiO}\right)$ on the other hand have a positive $\Delta G^{0}$, indicating $\mathrm{TiO}_{2}$ should be stable according to this correlation, which is indeed the case. This clearly demonstrates that while reducibility should be taken into account for the possible suboxide formation, the main driving force for oxide destabilization is its affinity to form hydroxides.

It is worth mentioning that two modes of performing LP-TEM can be used, namely TEM and STEM mode. In TEM mode, the electron beam is spread and illuminates the region of interest uniformly, which results in a uniform distribution of electrons and a constant concentration of radiolysis products. In our work, STEM mode was used, in which a sub-nanometer probe is scanned across the region of interest. The dwell time (time the probe spends at a single point in the raster) is usually in the same order of magnitude as the lifetime of the radiolysis products. This means that not all regions of the scanned particle are exposed to the radiolysis products at the same time. Considering that the scanning is always in 1 direction, this could lead to directionality in electron beam induced effects. In fact, the previously mentioned selective etching that was observed for silica is a result of this effect $[52,54]$. The higher electron dose rates of the STEM probe, could also allow effects that only occur above a certain threshold of electron dose rate to take place easier in STEM than in TEM, such as nucleation [69]. However, as liquid radiolysis plays a pivotal role in the oxide dissolution and occurs in both TEM and STEM, apart from potential directionality of the dissolution process the end result should be similar.

The exact mechanism through which the electron beam causes the oxides to degrade in the presence of $\mathrm{H}_{2} \mathrm{O}$, is likely very complex and oxide-dependent. Based on first-principle calculations, it has been suggested that the formation of oxygen vacancies by the electron beam, followed by rapid dissolution of neighboring metal atoms is the main mechanism [55]. This would however suggest that reducible oxides, in which oxygen vacancies form more easily, should be less stable, while the opposite is observed in our experiments. As stated above and demonstrated in this study, reducibility should be considered to account for the formation of suboxides, but the stability is clearly correlated to hydroxide formation from respective (sub)oxides.

For amorphous silica, it has recently been found that the mechanism likely involves the acceleration of silica hydroxylation and subsequent dissolution through the electron beam induced formation of reducing radicals capable of breaking the $\mathrm{Si}-\mathrm{O}-\mathrm{Si}$ bonds [54]. Suppressing the formation of these radicals by using a 1:1 acetic acid/sodium acetate buffer as radical scavenger, resulted in a more stable silica. In the same study, a test with a $1: 1 \mathrm{H}_{3} \mathrm{PO}_{4} / \mathrm{NaH}_{2} \mathrm{PO}_{4}$ buffer did not change the silica stability compared to pure water, indicating that $\mathrm{pH}$ change or buffering did not influence the stability of silica significantly. However, when employing the same strategy of adding a $0.2 \mathrm{~mol} \cdot \mathrm{L}^{-1}$ acetic acid/sodium acetate buffer to suppress radical formation and stabilize $\mathrm{Al}_{2} \mathrm{O}_{3}$, no significant improvement in stability was observed (Fig. S7 in the ESM), which suggests a different mechanism, but again likely not influenced by $\mathrm{pH}$ changes or buffering.

Based on previous work $[54,55]$ and this study, we can conclude that while the proposed formation of oxygen vacancies can still take place, especially at high electron beam dose rates [55], it is likely not a universal mechanism of oxide dissolution, nor the driving force. Oxide (and suboxide) hydration seems to be a key factor in determining their stability, but the exact mechanism of oxide dissolution in LP-TEM is clearly a very complex process and likely unique for each oxide. Therefore, further experimental work as well as theoretical modeling that will take the Gibbs free energy of hydration into account, is needed to unravel the mechanism of these processes.

\section{Conclusions}

In view of the growing popularity of LP-TEM in academic and industrial research, in particular for studying metal (oxide) systems in an aqueous environment, this study represents a critical step towards deepening our understanding of the diverse behaviors of metal oxides in LP-TEM. The origin of the varying stability of the oxide materials in LP-TEM environment is shown to correlate strongly with the oxide's Gibbs free energy of hydration. Other physio-chemical properties such as porosity, surface area or crystallinity of the oxide material are shown to be of limited importance in LP-TEM experiments. Furthermore, these results point to the need of redesigning the LP-TEM experiments such that hydration is suppressed when oxides with thermodynamic affinity towards forming hydroxides are studied.

Most importantly, the correlation found in this study can aid in predicting the stability of oxides without performing elaborate and time-consuming LP-TEM experiments. Several oxides which were identified in our study as very stable are also excellent candidates for studying important dynamic nanoscale processes for which high electron doses would be required. For instance, LP-TEM provides an excellent platform for studying the diffusion behavior and movement of nanometer size particles. Next to this, using LP-TEM to study catalyst evolution during synthesis and its structural changes during catalysis, has a tremendous potential to unravel phenomena that have never been observed or only indirectly investigated until now. Considering that heterogeneous catalysts typically consist of metal nanoparticles supported on an oxide, and that high electron doses are required for their visualization, using oxides that are stable in LP-TEM is a prerequisite for further studies in this field.

\section{Methods}

\subsection{Oxides}

The oxides used in this investigation were commercially available oxides, except for the amorphous Stöber silica spheres and the amorphous titania, which were prepared according to the procedures outlined below. The other oxides were P25 $\mathrm{TiO}_{2}$ (Evonik Degussa), Puralox $\gamma-\mathrm{Al}_{2} \mathrm{O}_{3} \mathrm{SCCa}-5 / 170$ (Sasol), $\mathrm{ZrO}_{2} \mathrm{XZ}$ catalyst support (SaintGobain), niobic acid (CBMM) and $\mathrm{MgO}$ nanopowder (Sigma-Aldrich). All oxides were used as received without additional treatment. Additionally, part of the niobic acid was calcined at $600{ }^{\circ} \mathrm{C}$ for $4 \mathrm{~h}$ with a heating and cooling rate of $5^{\circ} \mathrm{C} \cdot \mathrm{min}^{-1}$ to obtain a water-free crystalline $\mathrm{Nb}_{2} \mathrm{O}_{5}$ nanopowder.

Spherical silica nanoparticles were prepared adopting the procedure from Stöber et al. [70]. In a typical experiment, a mixture of $11.25 \mathrm{~mL}$ of $\mathrm{NH}_{3}$ solution (30 wt.\%, Merck) and $230 \mathrm{~mL}$ ethanol was heated to $35^{\circ} \mathrm{C}$ in an oil bath. $17.3 \mathrm{~mL}$ of tetraethyl orthosilicate (TEOS, 98\%, Sigma-Aldrich) was subsequently added to this mixture and then left to stir $(250 \mathrm{rpm})$ at $35^{\circ} \mathrm{C}$ for $16 \mathrm{~h}$. The solution was then neutralized with nitric acid (65\%, Sigma-Aldrich) and the liquid removed by 
rotary evaporation. The remaining solid was dried overnight at $120^{\circ} \mathrm{C}$, followed by calcination in air at $200{ }^{\circ} \mathrm{C}$ for $2 \mathrm{~h}, 400{ }^{\circ} \mathrm{C}$ for $1 \mathrm{~h}$ and subsequently $3 \mathrm{~h}$ at $800{ }^{\circ} \mathrm{C}$, all with a heating and cooling rate of $1.7^{\circ} \mathrm{C} \cdot \mathrm{min}^{-1}$. The resulting silica particles were spherical with a bimodal size distribution in the range of 20-30 and 60-120 nm.

Amorphous titania was prepared according to the procedure of Wang et al. [71] from a sol-gel hydrolysis precipitation of titanium isopropoxide $\mathrm{Ti}\left(\mathrm{OC}_{3} \mathrm{H}_{7}\right)_{4}$, (Sigma-Aldrich, $\geq 97 \%$ ). $2.0 \mathrm{~g}$ of titanium isopropoxide was dissolved in $4.2 \mathrm{~mL}$ of anhydrous ethanol in a glovebox. Then the solution was taken out of the glovebox and added dropwise with rigorous stirring at $500 \mathrm{rpm}$ to $4.5 \mathrm{~mL}$ of a $16.5 \mathrm{wt} . \%$ water in ethanol solution for a final water:alkoxide molar ratio of 5:1. White precipitates of hydrous oxide formed immediately. After the solutions were completely mixed, the mixture was left stirring for $2 \mathrm{~h}$ and subsequently transferred to an autoclave to gelate at $80^{\circ} \mathrm{C}$ for one day. Then the precipitate was separated from the mother liquor by centrifugation at 5,000 rpm and washed with demineralized water 3 times. The sample was subsequently dried at room temperature for one week.

\subsection{Characterization}

All oxides were characterized by powder X-ray diffraction (XRD) using a Brücker D2 Phaser with a Co $K_{a 1}$ source for phase identification. Samples were evaluated for $2 \theta$ between $25^{\circ}$ and $90^{\circ}$, except for the amorphous $\mathrm{TiO}_{2}$ which was evaluated up to $75^{\circ}$.

To determine morphology, the oxides were examined with TEM using a Talos F200X (Thermo Fischer Scientific), operated at $200 \mathrm{kV}$ acceleration voltage in both TEM and HAADF-STEM mode. The samples were dispersed in isopropanol (Honeywell, Chromasolv ${ }^{\mathrm{TM}}$ 99.9\%) and deposited on a 200 mesh copper-formvar grid. Vacuum control experiments were performed by continuous STEM scanning for $1 \mathrm{~h}$ using a beam current of $0.21 \mathrm{nA}$, as determined by the fluscreen current measured without a holder present. For the control experiments in vacuum, imaging was performed at $225,000 \times$ magnification, corresponding to a $500 \mathrm{~nm} \times 500 \mathrm{~nm}$ image size, resulting in an average dose rate of $5.2 \times 10^{3} \mathrm{e}^{-} \cdot \mathrm{nm}^{-2} \cdot \mathrm{s}^{-1}$. Images were collected with a pixel dwell time of $9.5 \mu$ s, with $1,024 \times 1,024$ pixel images, for a total of $10 \mathrm{~s} /$ frame.

TGA was performed using a PerkinElmer Pyris1 TGA instrument. Samples were heated from room temperature to $50{ }^{\circ} \mathrm{C}$ and held there for $10 \mathrm{~min}$ to stabilize the sample. Then the sample was heated to $600{ }^{\circ} \mathrm{C}$ at a rate of $2{ }^{\circ} \mathrm{C} \cdot \mathrm{min}^{-1}$ in a gas mixture of $20 \% \mathrm{O}_{2}$ in Ar. Exhaust gases were analyzed by mass spectrometry (MS) using an Omnistar MS instrument from Pfeiffer Vacuum.

$\mathrm{N}_{2}$ physisorption measurements were performed at $-196^{\circ} \mathrm{C}(77 \mathrm{~K})$ using a Micromeritics Tristar 3000 instrument. Before the isotherm measurements, samples were dried between 150 and $250{ }^{\circ} \mathrm{C}$ under vacuum. The appropriate drying temperature was selected based on TGA results and kept as low as possible to prevent sample transformation. Specific surface areas were calculated using the multipoint BET method $\left(0.05<p / p_{0}<0.25\right)$. Pore volume was determined at $p / p_{0}=0.9$ from the adsorption branches of the isotherms using the Barett-Joyner-Halenda (BJH) method. Microporosity was evaluated using the $t$-plot method.

\subsection{LP-TEM experiments}

A small amount of the oxide was dispersed in $2 \mathrm{~mL}$ of high-purity isopropanol (Honeywell, Chromasolv ${ }^{\mathrm{TM}}$ 99.9\%) and sonicated for at least $15 \mathrm{~min}$ to disperse agglomerates. A $0.5 \mu \mathrm{L}$ droplet of this suspension was placed and left for $5 \mathrm{~min}$ to evaporate on the silicon nitride $\left(\mathrm{Si}_{x} \mathrm{~N}_{y}\right)$ layer of the large silicon liquid cell chip with a nominally $50 \mathrm{~nm}$ thick $\mathrm{Si}_{x} \mathrm{~N}_{y}$ window with dimensions of $20 \mu \mathrm{m} \times$ $550 \mu \mathrm{m}$ (Protochips Inc., USA). In this manner the oxide particles are attached to the window, allowing them to be imaged and studied for a sufficient amount of time under electron beam irradiation in an aqueous environment.

A small silicon chip also containing a $20 \mu \mathrm{m} \times 550 \mu \mathrm{m} \mathrm{Si} x \mathrm{~N}_{y}$ window and $150 \mathrm{~nm}$ gold spacers to separate the two chips, was then placed in the dedicated liquid cell TEM holder (Protochips Inc., USA), a $1 \mu \mathrm{L}$ drop of water (sterile-filtered, Bioreagent, $\leq 1 \mathrm{Eu} \cdot \mathrm{mL}^{-1}, \leq 5 \mathrm{ppm}$ metal impurities, Sigma-Aldrich) was added on top of it and the cell was subsequently assembled by placing the large silicon chip containing the oxide sample on top. In this configuration, the sample is dispersed on the top chip when the holder is inserted in the microscope for optimal spatial resolution in STEM mode [26]. Both the large and small chip were plasma cleaned in an $80 \% \mathrm{Ar} / 20 \% \mathrm{O}_{2}$ plasma for two minutes before the sample was dispersed to render the chip surface hydrophilic.

Imaging was performed using a Talos F200X (Thermo Fischer Scientific), operated in scanning transmission mode (STEM) mode at $200 \mathrm{kV}$ acceleration voltage and using an HAADF detector for imaging. The imaging was performed with a beam current of $0.21 \mathrm{nA}$, as determined by the screen current without a holder present in the electron microscope and with a camera length of $125 \mathrm{~mm}$. Images were collected with a pixel dwell time of $9.5 \mu \mathrm{s}$, with $1,024 \times 1,024$ pixel images, for a total of $10 \mathrm{~s} /$ frame. Experiments were performed at multiple magnifications between 57,000 $\times$ and $320,000 \times$, resulting in an image size of $2,000 \mathrm{~nm} \times 2,000 \mathrm{~nm}$ and $360 \mathrm{~nm} \times 360 \mathrm{~nm}$, respectively, which also corresponds to the area exposed to the scanning electron beam and allows control of the dose rate and total dose the sample receives. The applied current in combination with these window sizes correspond to dose rates between $3.3 \times 10^{2}$ and $1.0 \times 10^{4} \mathrm{e}^{-} \cdot \mathrm{nm}^{-2} \cdot \mathrm{s}^{-1}$.

Each liquid cell experiment was performed in flow mode using a flow of $2 \mu \mathrm{L} \cdot \mathrm{min}^{-1}$ to prevent the buildup of gases and bubble formation due to electron beam induced water decomposition. Before the start of each experiment, the presence of water was verified by checking for contrast differences between the corners of the liquid cell and the middle at low magnification, which is evidence for significant differences in thickness of the water layer as a result of bowing of the $\mathrm{Si}_{x} \mathrm{~N}_{y}$ membrane. An example of such contrast gradient is presented in Fig. S8 in the ESM. For the oxides that degraded appreciably ( $\mathrm{MgO}, \mathrm{Al}_{2} \mathrm{O}_{3}$ and $\mathrm{SiO}_{2}$ ), at most 200 images were acquired, corresponding to approximately $33 \mathrm{~min}$ of continuous electron beam scanning. In the case the sample already completely disappeared beforehand, at least 10 additional images were acquired . For the other, more stable oxides, a total of 360 images were acquired, corresponding to exactly $1 \mathrm{~h}$ of continuous electron beam scanning. For all stable oxides and for $\mathrm{SiO}_{2}$, the magnification used was the same as in the vacuum experiments, namely $225,000 \times$, corresponding to a dose rate of $5.2 \times 10^{3} \mathrm{e}^{-} \cdot \mathrm{nm}^{-2} \cdot \mathrm{s}^{-1}$. For $\mathrm{Al}_{2} \mathrm{O}_{3}$ and $\mathrm{MgO}$, different experiments with different magnifications were performed, with the image sizes and corresponding electron dose rates listed in Tables S2 and S3 in the ESM.

Due to the very local nature of the electron beam induced degradation and dissolution, the overall amount of material dissolving is too low to be detectable in the liquid coming from the outlet of the liquid cell system (a concentration of less than $1 \mathrm{ng}$ metal per litre in the $\mathrm{MgO}$ experiments and even lower for the $\mathrm{Al}_{2} \mathrm{O}_{3}$ and $\mathrm{SiO}_{2}$ experiments), analysis of the liquid was not performed. To obtain a semi-quantitative assessment of the stability of the $\mathrm{SiO}_{2}, \mathrm{Al}_{2} \mathrm{O}_{3}$ and $\mathrm{MgO}$, the number of electrons required to remove a single atom was calculated. First the total number of electrons received by the sample during the experiment was calculated from the current, the total irradiation time and surface area of the STEM image. The number of atoms lost was determined from the lost volume by using bulk density and molecular weight for each oxide. Volumes lost, electron dose rates, duration of scanning and the resulting number of electrons required per removed atom are listed in Tables $\mathrm{S} 1-\mathrm{S} 3$ in the ESM for each experiment of $\mathrm{SiO}_{2}, \mathrm{Al}_{2} \mathrm{O}_{3}$ and $\mathrm{MgO}$, respectively. 
The volume of the material that has disappeared, was calculated by, in the case of $\mathrm{SiO}_{2}$ and $\mathrm{MgO}$, measuring length and width of all individual particles and calculating the total volume present before and after the experiment, assuming particles to be perfect ellipsoids with the third axis being equal to the shortest axis of the projected ellipse.

In the case of $\mathrm{Al}_{2} \mathrm{O}_{3}$, image analysis was performed using ImageJ. First, background was subtracted from the image and subsequently noise was reduced by using the despeckle function, which replaces each pixel with the median value of the $3 \times 3$ grid around it. Then, assuming a linear relationship between intensity and thickness, an intensity of 0 was assumed to correspond to no $\mathrm{Al}_{2} \mathrm{O}_{3}$ being present and the maximum intensity observed was assumed to correspond to the width of the associated particle. Then the total $\mathrm{Al}_{2} \mathrm{O}_{3}$ volume was determined by integrating over the entire image.

\section{Acknowledgements}

The authors gratefully acknowledge J. D. Meeldijk for technical assistance with the electron microscope, R. Dalebout, L. Weber and P. Paalanen for the $\mathrm{N}_{2}$ physisorption measurements, M. Versluijs-Helder for the TGA-MS measurements, S. M. C. de Jong for help with the synthesis of the amorphous $\mathrm{TiO}_{2}$ and $\mathrm{C}$. Hernandez Meija for providing the $\mathrm{Nb}_{2} \mathrm{O}_{5}$ samples. K. P. de Jong and M.J. Meijerink acknowledge funding from the European Research Council, an EU FP7 ERC Advanced Grant no. 338846. J. Zečević acknowledges financial support by Netherlands Organization for Scientific Research (NWO), Veni Grant No. 722.015.010.

Electronic Supplementary Material: Supplementary material (the $\mathrm{N}_{2}$ physisorption isotherms, the X-ray diffraction patterns, the TGA profiles, images before and after the control experiments of electron beam exposure in vacuum for each oxide, a comparison of $\mathrm{Al}_{2} \mathrm{O}_{3}$ in $\mathrm{H}_{2} \mathrm{O}$ and $\mathrm{Al}_{2} \mathrm{O}_{3}$ in an acetic acid/sodium acetate buffer in $\mathrm{H}_{2} \mathrm{O}$, a HAADF-STEM image displaying window bowing and snapshots of the movies of each oxide in the liquid cell being exposed to the electron beam, the associated movie of each oxide is also available) is available in the online version of this article at https://doi.org/ 10.1007/s12274-019-2419-3.

Open Access: This article is licensed under a Creative Commons Attribution 4.0 International License, which permits use, sharing, adaptation, distribution and reproduction in any medium or format, as long as you give appropriate credit to the original author(s) and the source, provide a link to the Creative Commons licence, and indicate if changes were made.

The images or other third party material in this article are included in the article's Creative Commons licence, unless indicated otherwise in a credit line to the material. If material is not included in the article's Creative Commons licence and your intended use is not permitted by statutory regulation or exceeds the permitted use, you will need to obtain permission directly from the copyright holder.

To view a copy of this licence, visit http://creativecommons.org/ licenses/by/4.0/.

\section{References}

[1] Casavola, M.; Hermannsdörfer, J.; de Jonge, N.; Dugulan, A. I.; de Jong, K. P. Fabrication of Fischer-Tropsch catalysts by deposition of iron nanocrystals on carbon nanotubes. Adv. Funct. Mater. 2015, 25, 5309-5319.

[2] Prieto, G.; Zečević, J.; Friedrich, H.; de Jong, K. P.; de Jongh, P. E. Towards stable catalysts by controlling collective properties of supported metal nanoparticles. Nat. Mater. 2013, 12, 34-39.

[3] Zečević, J.; Vanbutsele, G.; de Jong, K. P.; Martens, J. A. Nanoscale intimacy in bifunctional catalysts for selective conversion of hydrocarbons. Nature 2015, 528, 245-248.
[4] Soled, S. Silica-supported catalysts get a new breath of life. Science 2015, 350, 1171-1172.

[5] Sanchez, F.; Sobolev, K. Nanotechnology in concrete-A review. Constr. Build. Mater. 2010, 24, 2060-2071.

[6] Fortunato, E.; Barquinha, P.; Martins, R. Oxide semiconductor thin-film transistors: A review of recent advances. Adv. Mater. 2012, 24, 2945-2986.

[7] Wang, Z. L.; Kong, X. Y.; Ding, Y.; Gao, P.; Hughes, W. L.; Yang, R.; Zhang, Y. Semiconducting and piezoelectric oxide nanostructures induced by polar surfaces. Adv. Funct. Mater. 2004, 14, 943-956.

[8] Wang, S. B.; Peng, Y. L. Natural zeolites as effective adsorbents in water and wastewater treatment. Chem. Eng. J. 2010, 156, 11-24.

[9] Müller, K. A.; Bednorz, J. G. The discovery of a class of high-temperature superconductors. Science 1987, 237, 1133-1139.

[10] Cao, X. Q.; Vassen, R.; Stoever, D. Ceramic materials for thermal barrier coatings. J. Eur. Ceram. Soc. 2004, 24, 1-10.

[11] Zhang, Z. B.; Wang, C. C.; Zakaria, R.; Ying, J. Y. Role of particle size in nanocrystalline $\mathrm{TiO}_{2}$-based photocatalysts. J. Phys. Chem. B 1998, 102, 10871-10878.

[12] Csicsery, S. M. Shape-selective catalysis in zeolites. Zeolites 1984, 4, 202-213.

[13] Haruta, M. Size- and support-dependency in the catalysis of gold. Catal. Today 1997, 36, 153-166.

[14] Kruska, K.; Lozano-Perez, S.; Saxey, D. W.; Terachi, T.; Yamada, T.; Smith, G. D. W. Nanoscale characterisation of grain boundary oxidation in cold-worked stainless steels. Corros. Sci. 2012, 63, 225-233.

[15] Zeng, R. C.; Zhang, J.; Huang, W. J.; Dietzel, W.; Kainer, K. U.; Blawert, C.; Ke, W. Review of studies on corrosion of magnesium alloys. Trans. Nonferrous Met. Soc. China 2006, 16, s763-s771.

[16] Mannhart, J.; Schlom, D. G. Oxide interfaces-An opportunity for electronics. Science 2010, 327, 1607-1611.

[17] Williams, D. B.; Carter, C. B. Transmission Electron Microscopy: A Textbook for Materials Science; Springer: London, 2009.

[18] Gramm, F.; Baerlocher, C.; McCusker, L. B.; Warrender, S. J.; Wright, P. A.; Han, B. D.; Hong, S. B.; Liu, Z.; Ohsuna, T.; Terasaki, O. Complex zeolite structure solved by combining powder diffraction and electron microscopy. Nature 2006, 444, 79-81.

[19] Yuan, C. Z.; Li, J. Y.; Hou, L. R.; Zhang, X. G.; Shen, L. F.; Lou, X. W. Ultrathin mesoporous $\mathrm{NiCo}_{2} \mathrm{O}_{4}$ nanosheets supported on $\mathrm{Ni}$ foam as advanced electrodes for supercapacitors. Adv. Funct. Mater. 2012, 22, 4592-4597.

[20] Saka, H.; Kamino, T.; Ara, S.; Sasaki, K. In situ heating transmission electron microscopy. MRS Bull. 2008, 33, 93-100.

[21] Mehraeen, S.; McKeown, J. T.; Deshmukh, P. V.; Evans, J. E.; Abellan, P.; Xu, P. H.; Reed, B. W.; Taheri, M. L.; Fischione, P. E.; Browning, N. D. A (S)TEM gas cell holder with localized laser heating for in situ experiments. Microsc. Microanal. 2013, 19, 470-478.

[22] Tao, F.; Crozier, P. A. Atomic-scale observations of catalyst structures under reaction conditions and during catalysis. Chem. Rev. 2016, 116, 3487-3539.

[23] Wagner, J. B.; Cavalca, F.; Damsgaard, C. D.; Duchstein, L. D. L.; Hansen, T. W. Exploring the environmental transmission electron microscope. Micron 2012, 43, 1169-1175.

[24] van den Berg, R.; Elkjaer, C. F.; Gommes, C. J.; Chorkendorff, I.; Sehested, J.; de Jongh, P. E.; de Jong, K. P.; Helveg, S. Revealing the formation of copper nanoparticles from a homogeneous solid precursor by electron microscopy. J. Am. Chem. Soc. 2016, 138, 3433-3442.

[25] Feng, X. F.; Chee, S. W.; Sharma, R.; Liu, K.; Xie, X.; Li, Q. Q.; Fan, S. S.; Jiang, K. L. In situ TEM observation of the gasification and growth of carbon nanotubes using iron catalysts. Nano Res. 2011, 4, 767-779.

[26] de Jonge, N.; Ross, F. M. Electron microscopy of specimens in liquid. Nat. Nanotechnol. 2011, 6, 695-704.

[27] Chen, X.; Li, C.; Cao, H. L. Recent developments of the in situ wet cell technology for transmission electron microscopies. Nanoscale 2015, 7, 4811-4819.

[28] Li, C.; Chen, X.; Liu, H. Y.; Fang, J. L.; Zhou, X. Q. In-situ liquid-cell TEM study of radial flow-guided motion of octahedral Au nanoparticles and nanoparticle clusters. Nano Res. 2018, 11, 4697-4707.

[29] Munnik, P.; de Jongh, P. E.; de Jong, K. P. Recent developments in the synthesis of supported catalysts. Chem. Rev. 2015, 115, 6687-6718.

[30] Mehrabadi, B. A. T.; Eskandari, S.; Khan, U.; White, R. D.; Regalbuto, J. R. A review of preparation methods for supported metal catalysts. Adv. Catal. 2017, 61, 1-35. 
[31] Xiong, H. F.; Pham, H. N.; Datye, A. K. Hydrothermally stable heterogeneous catalysts for conversion of biorenewables. Green Chem. 2014, 16, 4627-4643.

[32] Ravenelle, R. M.; Copeland, J. R.; Kim, W. G.; Crittenden, J. C.; Sievers, C. Structural changes of $\gamma-\mathrm{Al}_{2} \mathrm{O}_{3}$-supported catalysts in hot liquid water. ACS Catal. 2011, 1, 552-561.

[33] Chee, S. W.; Pratt, S. H.; Hattar, K.; Duquette, D.; Ross, F. M.; Hull, R. Studying localized corrosion using liquid cell transmission electron microscopy. Chem. Commun. 2015, 51, 168-171.

[34] Gu, M.; Parent, L. R.; Mehdi, B. L.; Unocic, R. R.; McDowell, M. T.; Sacci, R. L.; Xu, W.; Connell, J. G.; Xu, P. H.; Abellan, P. et al. Demonstration of an electrochemical liquid cell for operando transmission electron microscopy observation of the lithiation/delithiation behavior of Si nanowire battery anodes. Nano Lett. 2013, 13, 6106-6112.

[35] Williamson, M. J.; Tromp, R. M.; Vereecken, P. M.; Hull, R.; Ross, F. M. Dynamic microscopy of nanoscale cluster growth at the solid-liquid interface. Nat. Mater. 2003, 2, 532-536.

[36] Yuk, J. M.; Park, J.; Ercius, P.; Kim, K.; Hellebusch, D. J.; Crommie, M. F.; Lee, J. Y.; Zettl, A.; Alivisatos, A. P. High-resolution EM of colloidal nanocrystal growth using graphene liquid cells. Science 2012, 336, 61-64.

[37] Ye, X. C.; Jones, M. R.; Frechette, L. B.; Chen, Q.; Powers, A. S.; Ercius, P.; Dunn, G.; Rotskoff, G. M.; Nguyen, S. C.; Adiga, V. P. et al. Singleparticle mapping of nonequilibrium nanocrystal transformations. Science 2016, 354, 874-877.

[38] Dai, L. L.; Sharma, R.; Wu, C. Y. Self-assembled structure of nanoparticles at a liquid-liquid interface. Langmuir 2005, 21, 2641-2643.

[39] Hendley IV, C. T.; Tao, J. H.; Kunitake, J. A. M. R.; de Yoreo, J. J.; Estroff, L. A. Microscopy techniques for investigating the control of organic constituents on biomineralization. MRS Bull. 2015, 40, 480-489.

[40] Smeets, P. J. M.; Cho, K. R.; Kempen, R. G. E.; Sommerdijk, N. A. J. M.; de Yoreo, J. J. Calcium carbonate nucleation driven by ion binding in a biomimetic matrix revealed by in situ electron microscopy. Nat. Mater. 2015, 14, 394-399.

[41] Elgrabli, D.; Dachraoui, W.; Ménard-Moyon, C.; Liu, X. J.; Bégin, D.; Bégin-Colin, S.; Bianco, A.; Gazeau, F.; Alloyeau, D. Carbon nanotube degradation in macrophages: Live nanoscale monitoring and understanding of biological pathway. ACS Nano 2015, 9, 10113-10124.

[42] Zheng, H. M.; Claridge, S. A.; Minor, A. M.; Alivisatos, A. P.; Dahmen, U. Nanocrystal diffusion in a liquid thin film observed by in situ transmission electron microscopy. Nano Lett. 2009, 9, 2460-2465.

[43] Pohlmann, E. S.; Patel, K.; Guo, S. J.; Dukes, M. J.; Sheng, Z.; Kelly, D. F. Real-time visualization of nanoparticles interacting with glioblastoma stem cells. Nano Lett. 2015, 15, 2329-2335.

[44] Radisic, A.; Vereecken, P. M.; Hannon, J. B.; Searson, P. C.; Ross, F. M. Quantifying electrochemical nucleation and growth of nanoscale clusters using real-time kinetic data. Nano Lett. 2006, 6, 238-242.

[45] Sacci, R. L.; Dudney, N. J.; More, K. L.; Parent, L. R.; Arslan, I.; Browning, N. D.; Unocic, R. R. Direct visualization of initial SEI morphology and growth kinetics during lithium deposition by in situ electrochemical transmission electron microscopy. Chem. Commun. 2014, 50, 2104-2107.

[46] Woehl, T. J.; Abellan, P. Defining the radiation chemistry during liquid cell electron microscopy to enable visualization of nanomaterial growth and degradation dynamics. J. Microsc. 2017, 265, 135-147.

[47] Kraus, T.; de Jonge, N. Dendritic gold nanowire growth observed in liquid with transmission electron microscopy. Langmuir 2013, 29, 8427-8432.

[48] Jungjohann, K. L.; Bliznakov, S.; Sutter, P. W.; Stach, E. A.; Sutter, E. A. In situ liquid cell electron microscopy of the solution growth of $\mathrm{Au}-\mathrm{Pd}$ core-shell nanostructures. Nano Lett. 2013, 13, 2964-2970.

[49] Abellan, P.; Mehdi, B. L.; Parent, L. R.; Gu, M.; Park, C.; Xu, W.; Zhang, Y. H.; Arslan, I.; Zhang, J. G.; Wang, C. M. et al. Probing the degradation mechanisms in electrolyte solutions for Li-ion batteries by in situ transmission electron microscopy. Nano Lett. 2014, 14, 1293-1299.

[50] Park, J.; Park, H.; Ercius, P.; Pegoraro, A. F.; Xu, C.; Kim, J. W.; Han, S. H.; Weitz, D. A. Direct observation of wet biological samples by graphene liquid cell transmission electron microscopy. Nano Lett. 2015, 15, 4737-4744.
[51] Nielsen, M. H.; Li, D. S.; Zhang, H. Z.; Aloni, S.; Han, T. Y. J.; Frandsen, C.; Seto, J.; Banfield, J. F.; Cölfen, H.; de Yoreo, J. J. Investigating processes of nanocrystal formation and transformation via liquid cell TEM. Microsc. Microanal. 2014, 20, 425-436.

[52] Zečević, J.; Hermannsdörfer, J.; Schuh, T.; de Jong, K. P.; de Jonge, N. Anisotropic shape changes of silica nanoparticles induced in liquid with scanning transmission electron microscopy. Small 2017, 13, 1602466.

[53] van de Put, M. W. P.; Carcouët, C. C. M. C.; Bomans, P. H. H.; Friedrich, H.; de Jonge, N.; Sommerdijk, N. A. J. M. Writing silica structures in liquid with scanning transmission electron microscopy. Small 2015, 11, 585-590.

[54] Meijerink, M. J.; Spiga, C.; Hansen, T. W.; Damsgaard, C. D.; de Jong, K. P.; Zečević, J. Nanoscale imaging and stabilization of silica nanospheres in liquid phase transmission electron microscopy. Part. Part. Syst. Charact. 2019, 36, 1800374 .

[55] Lu, Y.; Geng, J. G.; Wang, K.; Zhang, W.; Ding, W. Q.; Zhang, Z. H.; Xie, S. H.; Dai, H. X.; Chen, F. R.; Sui, M. L. Modifying surface chemistry of metal oxides for boosting dissolution kinetics in water by liquid cell electron microscopy. ACS Nano 2017, 11, 8018-8025.

[56] Thommes, M.; Kaneko, K.; Neimark, A. V.; Olivier, J. P.; RodriguezReinoso, F.; Rouquerol, J.; Sing, K. S. W. Physisorption of gases, with special reference to the evaluation of surface area and pore size distribution (IUPAC Technical Report). Pure Appl. Chem. 2015, 87, 1051-1069.

[57] Hernández Mejía, C.; den Otter, J. H.; Weber, J. L.; de Jong, K. P. Crystalline niobia with tailored porosity as support for cobalt catalysts for the Fischer-Tropsch synthesis. Appl. Catal. A Gen. 2017, 548, 143-149.

[58] Ropp, R. C. Encyclopedia of the Alkaline Earth Compounds; Elsevier: Amsterdam, 2013.

[59] Koh, A. L.; Gidcumb, E.; Zhou, O.; Sinclair, R. The dissipation of field emitting carbon nanotubes in an oxygen environment as revealed by in situ transmission electron microscopy. Nanoscale 2016, 8, 16405-16415.

[60] Schweitzer, G. K.; Pesterfield, L. L. The Aqueous Chemistry of the Elements; Oxford University Press: Oxford, 2010.

[61] Schneider, N. M.; Norton, M. M.; Mendel, B. J.; Grogan, J. M.; Ross, F. M.; Bau, H. H. Electron-water interactions and implications for liquid cell electron microscopy. J. Phys. Chem. C 2014, 118, 22373-22382.

[62] Robie, R. A.; Hemingway, B. S.; Fisher, J. R. Thermodynamic Properties of Minerals and Related Substances at $298.15 \mathrm{~K}$ and 1 Bar (10 Pascals) Pressure and at Higher Temperatures. United States Department of the Interior, Geological Survey: Washington, DC, 1978.

[63] Wesolowski, D. J.; Ziemniak, S. E.; Anovitz, L. M.; Machesky, M. L.; Bénézeth, P.; Palmer, D. A. Solubility and surface adsorption characteristics of metal oxides. In Aqueous Systems at Elevated Temperatures and Pressures. Palmer, D. A.; Fernández-Prini, R.; Harvey, A. H., Eds.; Elsevier: Amsterdam, 2004; pp 493-595.

[64] Perry, R. H.; Green, D. W. Perry's Chemical Engineers' Handbook, 8th ed.; McGraw-Hill: New York, 2008.

[65] Peiffert, C.; Nguyen-Trung, C.; Palmer, D. A.; Laval, J. P.; Giffaut, E. Solubility of $\mathrm{B}-\mathrm{Nb}_{2} \mathrm{O}_{5}$ and the hydrolysis of niobium(V) in aqueous solution as a function of temperature and ionic strength. J. Solution Chem. 2010, 39, 197-218.

[66] Lencka, M. M.; Anderko, A.; Riman, R. E. Hydrothermal precipitation of lead zirconate titanate solid solutions: Thermodynamic modeling and experimental synthesis. J. Am. Ceram. Soc. 1995, 78, 2609-2618.

[67] Söhnel, O.; Garside, J. Precipitation: Basic Principles and Industrial Applications; Butterworth-Heinemann: Boston, 1992.

[68] Tanabe, K. Niobic acid as an unusual acidic solid material. Mater. Chem. Phys. 1987, 17, 217-225.

[69] Abellan, P.; Woehl, T. J.; Parent, L. R.; Browning, N. D.; Evans, J. E.; Arslan, I. Factors influencing quantitative liquid (scanning) transmission electron microscopy. Chem. Commun. 2014, 50, 4873-4880.

[70] Stöber, W.; Fink, A.; Bohn, E. Controlled growth of monodisperse silica spheres in the micron size range. J. Colloid Interface Sci. 1968, 26, 62-69.

[71] Wang, C. C.; Ying, J. Y. Sol-gel synthesis and hydrothermal processing of anatase and rutile titania nanocrystals. Chem. Mater. 1999, 11, 3113-3120. 